\title{
Unplanned readmission within 90 days after pediatric neurosurgery
}

\author{
Silky Chotai, MD, Bradley S. Guidry, BS, Emily W. Chan, BS, Katherine D. Sborov, BA, \\ Stephen Gannon, BS, Chevis Shannon, MBA, DrPH, Christopher M. Bonfield, MD, \\ John C. Wellons III, MD, MSPH, and Robert P. Naftel, MD
}

Department of Neurosurgery, Division of Pediatric Neurosurgery, and Surgical Outcomes Center for Kids (SOCKs), Monroe Carell Jr. Children's Hospital, Vanderbilt University Medical Center, Nashville, Tennessee

\begin{abstract}
OBJECTIVE Readmission and return to operating room after surgery are increasingly being used as a proxy for quality of care. Nearly $60 \%$ of these readmissions are unplanned, which translates into billions of dollars in health care costs. The authors set out to analyze the incidence of readmission at their center, to define causes of unplanned readmission, and to determine the preoperative and surgical variables associated with readmissions following pediatric neurosurgery. METHODS A total of 536 children who underwent operations for neurosurgical diagnoses between 2012 and 2015 and who were later readmitted were included in the final analysis. Unplanned readmissions were defined to have occurred as a result of complications within 90 days after index surgery. Patient records were retrospectively reviewed to determine the primary diagnosis, surgery indication, and cause of readmission and return to operating room. The cost for index hospitalization, readmission episode, and total cost were derived based on the charges obtained from administrative data. Bivariate and multivariable analyses were conducted.
\end{abstract}

RESULTS Of 536 patients readmitted in total, $17.9 \%(n=96)$ were readmitted within 90 days. Of the overall readmissions, $11.9 \%(n=64)$ were readmitted within 30 days, and $5.97 \%(n=32)$ were readmitted between 31 and 90 days. The median duration between discharge and readmission was 20 days (first quartile [Q1]: 9 days, third quartile [Q3]: 36 days). The most common reason for readmission was shunt related $(8.2 \%, n=44)$, followed by wound infection $(4.7 \%, n$ $=25$ ). In the risk-adjusted multivariable logistic regression model for total 90 -day readmission, patients with the following characteristics: younger age $(p=0.001, \mathrm{OR} 0.886,95 \% \mathrm{Cl} 0.824-0.952)$; "other" (nonwhite, nonblack) race $(p=0.024$, OR 5.49, 95\% Cl 1.246-24.2); and those born preterm ( $p=0.032$, OR 2.1, 95\% Cl 1.1-4.12) had higher odds of being readmitted within 90 days after discharge. The total median cost for patients undergoing surgery in this study cohort was $\$ 11,520$ (Q1: \$7103, Q3: \$19,264). For the patients who were readmitted, the median cost for a readmission episode was \$8981 (Q1: \$5051, Q3: \$18,713).

CONCLUSIONS Unplanned 90-day readmissions in pediatric neurosurgery are primarily due to CSF-related complications. Patients with the following characteristics: young age at presentation; "other" race; and children born preterm have a higher likelihood of being readmitted within 90 days after surgery. The median cost was $>\$ 8000$, which suggests that the readmission episode can be as expensive as the index hospitalization. Clearly, readmission reduction has the potential for significant cost savings in pediatric neurosurgery. Future efforts, such as targeted education related to complication signs, should be considered in the attempt to reduce unplanned events. Given the single-center, retrospective study design, the results of this study are primarily applicable to this population and cannot necessarily be generalized to other institutions without further study.

https://thejns.org/doi/abs/10.3171/2017.6.PEDS17117

KEY WORDS unplanned readmission; costs; pediatric neurosurgery

$\mathrm{T}$ 1 he Centers for Medicare and Medicaid Services initiated the hospital readmission reduction program under which hospitals are penalized for readmissions rates exceeding the set Medicare benchmark for readmission in the adult patient population.,44 The penalty has increased from $1 \%$ to $3 \%$ in recent years. ${ }^{7,13,28}$ With expansion of the readmission reduction program, pediatric readmissions are rapidly coming under scru-

ABBREVIATIONS AUC = area under the curve; ETV-CPC = endoscopic third ventriculostomy-choroid plexus cauterization; EVD = external ventricular drain; LOS = length of hospital stay; $\mathrm{Q} 1, \mathrm{Q} 3$ = first quartile, third quartile; $\mathrm{ROC}=$ receiver operating characteristic.

SUBMITTED March 6, 2017. ACCEPTED June 16, 2017.

INCLUDE WHEN CITING Published online October 13, 2017; DOI: 10.3171/2017.6.PEDS17117. 
tiny. ${ }^{27,30}$ The Pediatric Quality Measures Program has recently identified pediatric readmission as the priority quality improvement measure. ${ }^{16}$

Pediatric readmissions are common and cost more than $\$ 1$ billion annually. ${ }^{8,16}$ The frequency of readmission ranges from $3 \%$ to $23 \%$, depending on the diagnosis for index hospitalization. ${ }^{10,41}$ Previous studies have demonstrated that pediatric readmissions are most strongly associated with the patients' specified primary payer, number of previous admissions, the diagnosis of a chronic complex condition, and longer length of hospital stay (LOS) during the initial admission..$^{8-10,16,27}$ However, these data from general pediatric readmissions cannot be applied to patients undergoing complex neurosurgical procedures.

Studies on readmission and reoperation associated with pediatric neurosurgical diagnoses are sparse. ${ }^{11,23,31,35,46} \mathrm{In}$ a single-center retrospective study of 1358 patients undergoing pediatric neurosurgery, Wrubel et al. ${ }^{46}$ reported $10.89 \%(\mathrm{n}=148)$ unexpected readmissions, and $8.02 \%(\mathrm{n}$ $=109$ ) related readmissions. Those authors found that in children with shunt-related surgery and shorter LOS, these variables were associated with related readmissions within 30 days of surgery. Chern et al. ${ }^{11}$ reported a $74.5 \%$ rate of readmission in the patients undergoing index surgery for shunt insertion or revision. Prior studies have limited the readmission to 30 days; however, the global episode of care period extends up to 90 days after discharge. ${ }^{34,39}$ The incidence of 90-day readmission, patient-specific and surgery-related factors associated with 90-day readmission, and related costs are not well reported in the literature. Given the potential implications of using readmissions as a measure of quality metrics, it is important to understand the reasons for and the modifiable factors associated with readmission..$^{12,29}$ Therefore, we set out to analyze its incidence at our center, to define causes of unplanned readmission following pediatric neurosurgical procedures, and to determine the preoperative and surgical variables associated with readmissions following pediatric neurosurgery.

\section{Methods}

Children undergoing surgery for neurosurgical diagnoses between January 2012 and March 2015 were analyzed. Institutional administrative data were queried for all index surgeries and readmissions within the specified study period. Inclusion criteria of the study were as follows: 1 ) children $<18$ years of age; 2) patients who underwent surgery within the prespecified study period; and 3) surgery was performed for neurological diagnoses. Patients who had the index surgery at another hospital were excluded, even though they had subsequent surgery at our institution.

Patient records were retrospectively reviewed to determine demographics, clinical variables, primary diagnosis, surgery indication, and reasons for readmission and return to operating room. Types of surgeries were categorized as brain tumor resection or biopsy; craniectomy or craniotomy (for epilepsy surgery, Chiari malformation, vascular lesion, and trauma); shunt surgery for hydrocephalus and pseudotumor cerebri; endoscopic third ventriculostomychoroid plexus cauterization (ETV-CPC); spine surgery (for deformity, myelomeningocele, tethered cord, spinal dysraphism, and isolated syringomyelia); and other (including angiograms, baclofen pump implantation, vagal nerve stimulator insertion, and craniosynostosis repair).

Readmission was defined as unplanned admission within 90 days after discharge following index surgery for neurosurgical diagnoses. The readmission event, reason for readmission, and date when the patient was readmitted were reviewed for two periods within the 90-day overall period: for readmissions within a 30-day period after discharge, and for readmissions between 31 and 90 days after discharge. Total 90-day readmission was calculated as the sum of the readmissions within 30 days and those between 31 and 90 days after discharge. Reasons for readmission were reviewed and categorized as shunt related (including shunt malfunction or revision and shunt infection), wound infection, other infection (systemic infection), CSF leak, pseudomeningocele, ETV-CPC failure, and medical complications (including any unplanned readmission that was not directly related to surgery). Return to operating room and reason for the return within 90 days after discharge were recorded.

The cost for the index hospitalization and readmission episode was obtained from the hospital billing department. These costs are estimated from the hospital's perspective by using the cost-to-charge ratio method. Such calculations have been used previously in the pediatric population. ${ }^{32}$ The cost for index hospitalization, readmission episode, and total cost are reported.

\section{Statistical Analysis}

The median and the first and third quartiles (Q1 and Q3) for continuous variables and the frequency for categorical variables were computed. Bivariate analyses were performed using the Mann-Whitney U-test for continuous variables and Fisher's exact test or chi-square test for categorical variables. Separate multivariable logistic regression models were built for total 90-day readmission, readmission within 30 days, and readmission between 31 and 90 days after surgery. The variables to be included in the model were chosen a priori. Variables including age at the time of surgery, sex, race, preterm birth (defined as birth at $<37$ weeks of gestation), surgery or procedure (including craniectomy or craniotomy, brain tumor resection or biopsy, shunt or ETV, spine surgery, and pre- or intraoperative external ventricular drain [EVD]), ICU stay, LOS, and postoperative complications were included in the models. Receiver operating characteristic (ROC) curve analysis was used to quantify the discrimination ability of multivariable logistic regression analysis. An area under the curve (AUC) for the ROC curve that is $<0.5$ is considered a random association; $0.6-0.7$ is considered some association; $0.71-0.8$ is considered adequate; and $>0.8$ is considered excellent. ${ }^{21} \mathrm{~A}$ subgroup analysis was conducted to determine readmission rates and causes of readmission in children $<2$ years of age. A p value $\leq 0.05$ was considered statistically significant. Analysis was performed using SPSS version 20 (IBM, Inc.).

\section{Results}

A total of 580 patients were included in the analysis. Of 
those, 44 patients were excluded for the following reasons: the index surgery was performed outside of the inclusion date range, the patients were $>18$ years old at the time of surgery, and the surgery was performed for nonneurosurgical diagnoses. A total of 536 patients with a median age of 6.3 years (Q1: 1.4 years, Q3: 11.4 years) were further analyzed.

Of the 536 patients, $17.9 \%(\mathrm{n}=96)$ were readmitted within 90 days, $11.9 \%(n=64)$ were readmitted within 30 days, and $5.97 \%(\mathrm{n}=32)$ were readmitted between 31 and 90 days. The median duration between discharge and readmission was 20 days (Q1: 9 days, Q3: 36 days). The most common reason for readmission was shunt related $(8.2 \%$, $n=44)$, followed by wound infection $(4.7 \%, n=25)$. The reasons for readmission are listed in Table 1 . With regard to return to operating room, a total of $12.5 \%(n=67)$ of children required a repeat operation within 90 days after surgery. The most common causes of 90-day return to operating room were shunt-related complications $(\mathrm{n}=37)$, wound-related complications ( $\mathrm{n}=14)$, and ETV-CPC failure $(\mathrm{n}=7)$.

Table 2 summarizes patient demographic, clinical, and surgery variables among those with and without 90-day readmission. The patients who were readmitted within 90 days were younger (median 2.9 years) compared with those who were not readmitted (median 7.7 years) $(\mathrm{p}<$ 0.0001 ). With regard to the surgical procedure, the patients undergoing shunt $(38.5 \%$ vs $27.7 \%, \mathrm{p}=0.036)$ or ETV-CPC $(14.6 \%$ vs $7.7 \%, p=0.024)$ surgery had a significantly higher frequency of readmissions within 90 days. The patients who were readmitted had a longer LOS during the index hospitalization (median 3 days vs median 2 days, $\mathrm{p}=0.002$ ).

In the risk-adjusted multivariable logistic regression model for total 90-day readmission, "other" (nonwhite, nonblack) race ( $\mathrm{p}=0.024$, OR 5.49, 95\% CI 1.246-24.2), and those born preterm ( $\mathrm{p}=0.032$, OR 2.1, 95\% CI 1.14.12) had higher odds of being readmitted within 90 days after discharge (Table 3). The odds of 90-day readmission decrease with increasing age ( $\mathrm{p}=0.001, \mathrm{OR} 0.886,95 \% \mathrm{CI}$ $0.824-0.952$ ). Therefore, the younger patients have higher odds of 90-day readmission ( $\mathrm{p}=0.001$, OR $1.12,95 \%$ CI 1.05-1.21). The AUC for the model's ROC curve was 0.71 . In a separate multivariable logistic regression model for 30 days, the variables "other" (nonwhite, nonblack), "race" ( $\mathrm{p}=0.021$, OR 5.916, 95\% CI 1.304-26.84), and "ICU stay" during index hospitalization $(\mathrm{p}=0.010, \mathrm{OR}$ $3.302,95 \%$ CI 1.325-8.231) were associated with higher 30-day readmission (Table 4). The AUC for the model's ROC curve was 0.72 .

In a subgroup analysis for the patients $<2$ years old, of the 150 patients who underwent surgery, $28.7 \%(n=43)$ were admitted within 90 days after discharge. The most common reasons for readmission were shunt-related complications $(10.7 \%, \mathrm{n}=16)$ and wound infection $(5.3 \%, \mathrm{n}=$ 8). The reasons for readmission are listed in Table 5 .

The total median cost for patients undergoing surgery in this study cohort was $\$ 11,520(\mathrm{Q} 1$ : \$7103, Q3: \$19,264). For the patients who were readmitted, the median cost for a readmission episode was \$8981 (Q1: \$5051, Q3: \$18,713).
TABLE 1. Reasons for 90 -day readmission in 536 children who underwent operations for neurosurgical diagnoses

\begin{tabular}{lc}
\hline \multicolumn{1}{c}{ Reasons for Readmission } & Value (\%) \\
\hline Shunt related-revision or malfunction & $44(8.2)$ \\
\hline Wound infection & $25(4.7)$ \\
\hline Medical complications ${ }^{*}$ & $14(2.6)$ \\
\hline Other† & $3(0.56)$ \\
\hline CSF leak & $10(1.9)$ \\
\hline Pseudomeningocele & $7(1.3)$ \\
\hline Infection, other & $5(0.9)$ \\
\hline ETV-CPC failure & $8(1.5)$ \\
\hline Spine, instrumentation failure & $1(0.2)$ \\
\hline Median time to readmission & 20 days-Q1, 9 days; \\
& Q3, 36 days \\
\hline
\end{tabular}

\footnotetext{
* Includes headache $(n=4)$, seizure $(n=4)$, altered mental status $(n=2)$, emesis $(n=2)$, and fever with or without neutropenia $(n=2)$.

$\dagger$ Includes wound dehiscence $(n=2)$ and chronic subdural hematoma $(n=1)$.
}

\section{Discussion}

Unplanned readmissions following pediatric neurosurgery procedures are undesirable and expensive for patients, parents, providers, and payers. ${ }^{2-4,6,19,30,36,44,45}$ Efforts focused on readmission reduction are therefore of utmost importance. The first step in that direction is to understand the causes of readmissions and to identify the preventable factors associated with readmission. In this study, approximately $11 \%$ of children were readmitted within 30 days, and $18 \%$ were readmitted within a total of 90 days after surgery. Unplanned 90-day readmissions were primarily due to shunt-related and wound complications. After controlling for an array of variables, the odds of readmission within 90 days were higher in children who were young at presentation, those born preterm, and children whose race was listed as "other." In addition, patients who had an ICU stay during their index hospitalization had higher odds of being readmitted within 30 days after surgery. Designing interventions targeted to these drivers of readmission has the potential to decrease readmissions and improve the quality of care.

Previous studies focusing on general pediatric diseases have demonstrated that the readmission rate is higher in young patients and in those born preterm. ${ }^{10,40,43,47} \mathrm{Com}-$ pared with older children, these groups of patients are considered more vulnerable to complications, resulting in a relatively lower threshold to admit these patients and, therefore, higher readmission rates. Furthermore, these patients have several associated conditions that might require a multidisciplinary team approach to determine physiological stability before discharge placement. Therefore, readmissions in these groups of patients may reflect an inadequate assessment of the child's readiness for discharge. In our study, in a subgroup analysis for patients $<2$ years old, the most common reasons for readmission were similar to those in children $\geq 2$ years. This suggests that although these subgroups of patients are more likely to be readmitted, similar readmission prevention strategies can be used in all children regardless of their age. 
TABLE 2. Demographic, clinical, and surgery variables in patients with and without 90-day readmission

\begin{tabular}{|c|c|c|c|c|}
\hline \multirow[b]{2}{*}{ Variable } & \multirow{2}{*}{$\begin{array}{l}\text { Total, } \\
\mathrm{N}=536\end{array}$} & \multicolumn{2}{|c|}{ 90-Day Readmission } & \multirow{2}{*}{$\begin{array}{c}p \\
\text { Value }\end{array}$} \\
\hline & & No, $n=440$ & Yes, $n=96$ & \\
\hline Median age in yrs (range) & $6.3(1.4-11.4)$ & $7.7(3.1-12.7)$ & $2.9(0.45-9.1)$ & $<0.0001$ \\
\hline Sex & & & & 0.128 \\
\hline Female & $263(49 \%)$ & $210(47.7 \%)$ & $53(55.2 \%)$ & \\
\hline Male & $269(50.2 \%)$ & $226(51.4 \%)$ & $43(44.8 \%)$ & \\
\hline Race & & & & 0.316 \\
\hline White & $422(78.7 \%)$ & $347(78.9 \%)$ & $75(78.1 \%)$ & \\
\hline Black & $88(16.4 \%)$ & $74(16.8 \%)$ & $14(14.6 \%)$ & \\
\hline Others & $24(4.5 \%)$ & $17(3.9 \%)$ & $7(7.3 \%)$ & \\
\hline Preterm birth at $<37$ wks & $141(26.3 \%)$ & $110(25.0 \%)$ & $31(32.3 \%)$ & 0.094 \\
\hline Insurance & & & & 0.716 \\
\hline Private & $267(49.8 \%)$ & $223(50.7 \%)$ & $44(45.8 \%)$ & \\
\hline Medicaid or Medicare & $222(41.4 \%)$ & $177(40.2 \%)$ & $45(46.9 \%)$ & \\
\hline Self-pay & $8(1.5 \%)$ & $7(1.6 \%)$ & $1(1.0 \%)$ & \\
\hline Other-i.e., military & $34(6.3 \%)$ & $28(6.4 \%)$ & $6(6.3 \%)$ & \\
\hline \multicolumn{5}{|l|}{ Diagnosis } \\
\hline Tethered cord, dysraphism, or MMC & $71(13.2 \%)$ & $62(14.1 \%)$ & $9(9.4 \%)$ & 0.098 \\
\hline Syrinx & $4(0.75 \%)$ & $3(0.68 \%)$ & $1(1.0 \%)$ & 0.061 \\
\hline Spine tumor & $7(1.3 \%)$ & $6(1.4 \%)$ & $1(1.0 \%)$ & 0.064 \\
\hline Spine deformity & $10(1.9 \%)$ & $10(2.3 \%)$ & 0 & - \\
\hline CM-I & $41(7.6 \%)$ & $35(7.9 \%)$ & $6(6.3 \%)$ & 0.374 \\
\hline Hydrocephalus & $194(36.2 \%)$ & $148(33.6 \%)$ & $46(47.9 \%)$ & 0.002 \\
\hline Pseudotumor cerebri & $7(1.3 \%)$ & $5(1.1 \%)$ & $2(2.1 \%)$ & 0.059 \\
\hline Brain tumor & $70(13.1 \%)$ & $58(13.2 \%)$ & $12(12.5 \%)$ & 0.303 \\
\hline Arachnoid cyst & $18(3.4 \%)$ & $17(3.9 \%)$ & $1(1.0 \%)$ & 0.230 \\
\hline Vascular & $27(5.0 \%)$ & $23(5.2 \%)$ & $4(4.2 \%)$ & 0.451 \\
\hline Trauma & $19(3.5 \%)$ & $18(4.1 \%)$ & $1(1.0 \%)$ & 0.117 \\
\hline Epilepsy & $33(6.2 \%)$ & $25(5.7 \%)$ & $8(8.3 \%)$ & 0.222 \\
\hline Craniosynostosis & $2(0.37 \%)$ & $1(0.23 \%)$ & $1(1.0 \%)$ & 0.575 \\
\hline Skull lesion & $9(1.7 \%)$ & $8(1.8 \%)$ & $1(1.0 \%)$ & 0.689 \\
\hline Spasticity & $27(5.0 \%)$ & $24(5.5 \%)$ & $3(3.1 \%)$ & 0.457 \\
\hline \multicolumn{5}{|l|}{ Procedure } \\
\hline Brain tumor/cyst resection or biopsy & $85(15.9 \%)$ & $72(16.4 \%)$ & $13(13.5 \%)$ & 0.899 \\
\hline $\begin{array}{l}\text { Craniectomy or craniotomy for epilepsy, vascular, } \\
\text { trauma, CM-I, \& other brain lesions }\end{array}$ & $81(15.1 \%)$ & $71(16.1 \%)$ & $10(10.4 \%)$ & 0.246 \\
\hline Shunt surgery & $159(29.7 \%)$ & $122(27.7 \%)$ & $37(38.5 \%)$ & 0.036 \\
\hline ETV-CPC & $48(9.0 \%)$ & $34(7.7 \%)$ & $14(14.6 \%)$ & 0.024 \\
\hline Spine surgery & $88(16.4 \%)$ & $79(18.0 \%)$ & $9(9.4 \%)$ & 0.064 \\
\hline Other* & $75(14.0 \%)$ & $62(14.1 \%)$ & $13(13.5 \%)$ & 0.183 \\
\hline Median op time in mins (range) & 143 (97-243) & $152(104-247)$ & $143(87-294)$ & 0.475 \\
\hline Median LOS in days (range) & $2(1-3)$ & $2(1-3)$ & $3(1-4)$ & 0.002 \\
\hline No. w/ ICU stay & $246(45.9 \%)$ & $197(44.8 \%)$ & $49(51.0 \%)$ & 0.158 \\
\hline No. w/ postop complications & $39(7.3 \%)$ & $31(7.1 \%)$ & $8(8.3 \%)$ & 0.397 \\
\hline Discharge destination & & & & 0.547 \\
\hline Home & $532(99.25 \%)$ & $437(99.3 \%)$ & $95(99 \%)$ & \\
\hline Non-home & $4(0.75 \%)$ & $3(0.68 \%)$ & $1(1.0 \%)$ & \\
\hline
\end{tabular}

$\mathrm{CM}-\mathrm{I}=$ Chiari malformation Type I; MMC = myelomeningocele.

Values represent the number of patients (\%) unless otherwise specified.

* Includes angiograms, baclofen pump, vagal nerve stimulator insertion, and craniosynostosis repair. 
TABLE 3. Multivariable logistic regression model for total 90-day readmission

\begin{tabular}{lcccc}
\hline & $\mathrm{p}$ & & \multicolumn{2}{c}{$95 \% \mathrm{Cl}$ for OR } \\
\cline { 5 - 5 } \multicolumn{1}{c}{ Variable } & Value & OR & Lower & Upper \\
\hline Age & 0.001 & 0.886 & 0.824 & 0.952 \\
\hline Sex & 0.693 & 0.875 & 0.487 & 1.613 \\
\hline Race & 0.066 & & & \\
\hline Black vs white & 0.495 & 0.785 & 0.325 & 1.894 \\
\hline Other vs white & 0.024 & 5.490 & 1.246 & 24.20 \\
\hline Preterm birth & 0.032 & 2.10 & 1.067 & 4.127 \\
\hline Surgery type & & & & \\
\hline Craniotomy or craniectomy & 0.573 & 0.697 & 0.199 & 2.440 \\
\hline Brain tumor resection or biopsy & 0.600 & 0.745 & 0.248 & 2.238 \\
\hline Shunt or ETV-CPC† & 0.742 & 0.873 & 0.387 & 1.968 \\
\hline Spine surgery & 0.346 & 3.27 & 0.279 & 38.33 \\
\hline Preop or intraop EVD & 0.975 & 0.979 & 0.261 & 3.669 \\
\hline Postop complications & 0.727 & 0.800 & 0.230 & 2.790 \\
\hline ICU stay & 0.086 & 2.013 & 0.906 & 4.474 \\
\hline LOS & 0.709 & 1.021 & 0.917 & 1.136 \\
\hline
\end{tabular}

* Craniotomy or craniectomy was performed for epilepsy surgery, Chiari malformation, vascular lesion, and trauma.

† Combined into a single variable due to the relatively small number of patients in the ETV-CPC group and to avoid overfitting of the model with multiple variables.

A number of studies in the adult and general pediatric literature have demonstrated the effect of race on readmission. ${ }^{1,7,10,13,15}$ Sherrod et al. have demonstrated that Native American patients have a higher risk for readmission following pediatric neurosurgery. ${ }^{38}$ We found that the children whose race was listed as "other" had higher odds of being readmitted after surgery. Given the relatively small sample size, the variables included in the model were limited; therefore, we may not have enough evidence to identify a definitive association of race with readmission. Furthermore, the issue of racial disparity and its association with readmission is complex and multidimensional. This disparity can be partly explained by cultural differences in expectations of family support, as well as socioeconomic status. ${ }^{1,14,24,33}$ Efforts at reducing unplanned events should be focused on more effective parent-doctor communication and on parent education, while taking language and cultural differences into consideration.

Consistent with our findings, a number of previous studies have demonstrated that CSF-related readmissions are the most common causes of readmissions in pediatric neurosurgery. ${ }^{5,11,31,38,42,46}$ Chern et al ${ }^{11}$ reported a $74.5 \%$ rate of readmission in patients undergoing index surgery for shunt insertion or revision. In a recent study in which a national database for 9799 pediatric neurosurgical patients was used, Sherrod et al. reported a $17.3 \%$ readmission rate associated with shunt revision. ${ }^{38}$ The higher rate of CSFrelated readmissions further supports the need to continue to combine resources by conducting research through multiinstitutional mechanisms such as the Hydrocephalus Clinical Research Network. ${ }^{25,26}$ Furthermore, for patients who are at high risk for readmissions, measures such as
TABLE 4. Multivariable logistic regression model for 30-day readmission

\begin{tabular}{|c|c|c|c|c|}
\hline \multirow[b]{2}{*}{ Variable } & \multirow{2}{*}{$\begin{array}{c}p \\
\text { Value }\end{array}$} & \multirow[b]{2}{*}{ OR } & \multicolumn{2}{|c|}{$95 \% \mathrm{Cl}$ for OR } \\
\hline & & & Lower & Upper \\
\hline Age & 0.104 & 0.937 & 0.867 & 1.013 \\
\hline Sex & 0.633 & 0.843 & 0.418 & 1.7 \\
\hline \multicolumn{5}{|l|}{ Race } \\
\hline Black vs white & 0.615 & 1.351 & 0.521 & 3.503 \\
\hline Other vs white & 0.021 & 5.916 & 1.304 & 26.84 \\
\hline Preterm birth & 0.131 & 1.859 & 0.831 & 4.156 \\
\hline \multicolumn{5}{|l|}{ Surgery type } \\
\hline Craniotomy or craniectomy* & 0.118 & 0.292 & 0.063 & 1.365 \\
\hline Brain tumor resection or biopsy & 0.569 & 0.709 & 0.216 & 2.32 \\
\hline Shunt or ETV-CPC $†$ & 0.374 & 0.647 & 0.248 & 1.689 \\
\hline Spine surgery & 0.426 & 2.804 & 0.222 & 35.457 \\
\hline Preop or intraop EVD & 0.959 & 1.039 & 0.243 & 4.441 \\
\hline Postop complications & 0.995 & 0.995 & 0.227 & 4.362 \\
\hline ICU stay & 0.01 & 3.302 & 1.325 & 8.231 \\
\hline LOS & 0.736 & 0.978 & 0.859 & 1.114 \\
\hline
\end{tabular}

* Craniotomy or craniectomy performed for epilepsy surgery, Chiari malformation, vascular lesion, and trauma.

$\dagger$ Combined into a single variable due to the relatively small number of patients in the ETV-CPC group, and to avoid overfitting of the model with multiple variables.

frequent postdischarge phone calls ${ }^{18}$ or postdischarge primary care pediatrician visits can be used to evaluate early signs of these complications, some of which can possibly be managed without the need to readmit. ${ }^{5,20,37}$

The 30-day readmission may be more influenced by the surgery or disease-related factors than is the 90-day readmission. Although our models were not inclusive of all potential variables that can impact readmission, the ICU stay (a proxy for severity and complexity) was significantly associated with 30-day readmission, but not 90 day readmission. We certainly need more data to support this conclusion; however, this association provides some evidence that the longer the time from discharge to readmission, the less likely the reason for readmission is to be associated with the index surgery.

The data on cost associated with unplanned pediatric neurosurgery readmissions is relatively sparse. Hedequist

TABLE 5. Reasons for readmission in a subgroup of 150 children $<2$ years old $(n=43)$

\begin{tabular}{cc}
\hline Reasons for Readmission & No. of Patients $(\%)$ \\
\hline Shunt related & $16(10.7)$ \\
\hline Wound infection & $8(5.3)$ \\
\hline ETV-CPC failure & $8(5.3)$ \\
\hline Other & $5(3.3)$ \\
\hline Infection, other & $2(1.3)$ \\
\hline CSF leak & $2(1.3)$ \\
\hline Pseudomeningocele & $2(1.3)$ \\
\hline
\end{tabular}


et al. reported hospital charges ranging from $\$ 26,977$ to $\$ 961,722$ for pediatric wound complications following surgery for spine deformity. ${ }^{22}$ Most studies have reported charges associated with readmission. The actual cost incurred for the episode of care is substantially lower than the hospital charges. ${ }^{17}$ We report the actual cost of the readmission episode, which is derived using the charge-to-cost ratio method. Although the reported costs represent an estimate of the cost incurred at a single center, it provides some evidence on the actual dollar amount spent for readmissions. The median cost was $>\$ 8000$, which suggests that the readmission episode can be as expensive as the index hospitalization. Clearly, readmission reduction has the potential for significant cost savings in pediatric neurosurgery.

This study has certain limitations. This is a retrospective analysis of single-center administrative data. The results of this study are primarily applicable to this population and cannot necessarily be generalized to other institutions without further investigation. The readmissions were identified based on the billing data. The inaccuracy and data deficiencies inherent to any administrative database must be considered while interpreting these results. To ensure accuracy, we reviewed 30- and 90-day readmissions for all the patients included in the study by chart review. The costs reported in our study reflect the single-center cost for the type of surgeries performed during the specified time duration. It is at best an estimation of cost to the hospital, and is derived based on the charges. The costs might be different when reported from the payer's perspective and the societal perspective.

The interpretation of the multivariable model is affected by the number and type of variables included in the analysis. The variables included in this analysis were chosen a priori based on clinical experience and literature review; however, given the limited number of variables captured in the administrative database and the overall small sample size, it is possible that variables that may impact readmission were not adjusted in the analysis. Finally, the number of patients readmitted within 90 days after surgery was relatively low; therefore, any negative associations should be interpreted with caution. Furthermore, the number of reasons for readmission was low; therefore, the drivers for each reason for readmission could not be identified. A larger sample size would allow the addition of more independent variables to the model, with the potential to identify other significant associations. Further studies using multicenter prospective data are needed to validate the findings of this study.

\section{Conclusions}

Unplanned 90-day readmissions in pediatric neurosurgery are primarily due to CSF-related complications. Patients who were young at presentation, whose race was categorized as nonwhite or nonblack, and those born preterm have a higher likelihood of being readmitted within 90 days after surgery. The median cost was $>\$ 8000$, which suggests that the readmission episode can be as expensive as the index hospitalization. Clearly, readmission reduction has the potential for significant cost savings in pediatric neurosurgery. Future efforts, such as targeted education related to complication signs, should be considered in the effort to reduce unplanned events. Given the single-center, retrospective study design, our results are primarily applicable to this population and cannot necessarily be generalized to other institutions without further study.

\section{References}

1. Adogwa O, Elsamadicy AA, Mehta AI, Cheng J, Bagley CA, Karikari IO: Racial disparities in 30-day readmission rates after elective spine surgery: a single institutional experience. Spine (Phila Pa 1976) 41:1677-1682, 2016

2. Akamnonu C, Cheriyan T, Goldstein JA, Lafage V, Errico TJ, Bendo JA: Unplanned hospital readmission after surgical treatment of common lumbar pathologies: rates and causes. Spine (Phila Pa 1976) 40:423-428, 2015

3. Akins PT, Harris J, Alvarez JL, Chen Y, Paxton EW, Bernbeck J, et al: Risk factors associated with 30-day readmissions after instrumented spine surgery in 14,939 patients: 30-day readmissions after instrumented spine surgery. Spine (Phila Pa 1976) 40:1022-1032, 2015

4. Amin BY, Tu TH, Schairer WW, Na L, Takemoto S, Berven S, et al: Pitfalls of calculating hospital readmission rates based on nonvalidated administrative data sets: presented at the 2012 Joint Spine Section Meeting: clinical article. J Neurosurg Spine 18:134-138, 2013

5. Appelgren T, Zetterstrand S, Elfversson J, Nilsson D: Longterm outcome after treatment of hydrocephalus in children. Pediatr Neurosurg 46:221-226, 2010

6. Aujesky D, Mor MK, Geng M, Stone RA, Fine MJ, Ibrahim SA: Predictors of early hospital readmission after acute pulmonary embolism. Arch Intern Med 169:287-293, 2009

7. Axon RN, Williams MV: Hospital readmission as an accountability measure. JAMA 305:504-505, 2011

8. Bardach NS, Vittinghoff E, Asteria-Peñaloza R, Edwards JD, Yazdany J, Lee HC, et al: Measuring hospital quality using pediatric readmission and revisit rates. Pediatrics 132:429436, 2013

9. Beckman JM, Amankwah EK, Tetreault LL, Perlman SA, Tuite GF: Complications associated with bacitracin powder in surgical wounds. J Neurosurg Pediatr 16:719-725, 2015

10. Berry JG, Toomey SL, Zaslavsky AM, Jha AK, Nakamura MM, Klein DJ, et al: Pediatric readmission prevalence and variability across hospitals. JAMA 309:372-380, 2013 (Erratum in JAMA 309:986, 2013)

11. Chern JJ, Bookland M, Tejedor-Sojo J, Riley J, Shoja MM, Tubbs RS, et al: Return to system within 30 days of discharge following pediatric shunt surgery. J Neurosurg Pediatr 13:525-531, 2014

12. Cima RR, Lackore KA, Nehring SA, Cassivi SD, Donohue JH, Deschamps C, et al: How best to measure surgical quality? Comparison of the Agency for Healthcare Research and Quality Patient Safety Indicators (AHRQ-PSI) and the American College of Surgeons National Surgical Quality Improvement Program (ACS-NSQIP) postoperative adverse events at a single institution. Surgery 150:943-949, 2011

13. Desai AS, Stevenson LW: Rehospitalization for heart failure: predict or prevent? Circulation 126:501-506, 2012

14. Dimick J, Ruhter J, Sarrazin MV, Birkmeyer JD: Black patients more likely than whites to undergo surgery at lowquality hospitals in segregated regions. Health Aff (Millwood) 32:1046-1053, 2013

15. Dotson JL, Kappelman MD, Chisolm DJ, Crandall WV: Racial disparities in readmission, complications, and procedures in children with Crohn's disease. Inflamm Bowel Dis 21:801-808, 2015

16. Dougherty D, Schiff J, Mangione-Smith R: The Children's Health Insurance Program Reauthorization Act quality measures initiatives: moving forward to improve measurement, 
care, and child and adolescent outcomes. Acad Pediatr 11 (3 Suppl):S1-S10, 2011

17. Finkler SA: The distinction between cost and charges. Ann Intern Med 96:102-109, 1982

18. Flippo R, NeSmith E, Stark N, Joshua T, Hoehn M: Reduction of 30-day preventable pediatric readmission rates with postdischarge phone calls utilizing a patient- and family-centered care approach. J Pediatr Health Care 29:492-500, 2015

19. Garrison GM, Mansukhani MP, Bohn B: Predictors of thirtyday readmission among hospitalized family medicine patients. J Am Board Fam Med 26:71-77, 2013

20. Hain PD, Gay JC, Berutti TW, Whitney GM, Wang W, Saville BR: Preventability of early readmissions at a children's hospital. Pediatrics 131:e171-e181, 2013

21. Hanley JA, McNeil BJ: The meaning and use of the area under a receiver operating characteristic (ROC) curve. Radiology 143:29-36, 1982

22. Hedequist D, Haugen A, Hresko T, Emans J: Failure of attempted implant retention in spinal deformity delayed surgical site infections. Spine (Phila Pa 1976) 34:60-64, 2009

23. Jain A, Puvanesarajah V, Menga EN, Sponseller PD: Unplanned hospital readmissions and reoperations after pediatric spinal fusion surgery. Spine (Phila Pa 1976) 40:856-862, 2015

24. Kersting RC: Impact of social support, diversity, and poverty on nursing home utilization in a nationally representative sample of older Americans. Soc Work Health Care 33:6787,2001

25. Kestle JR, Holubkov R, Douglas Cochrane D, Kulkarni AV, Limbrick DD Jr, Luerssen TG, et al: A new Hydrocephalus Clinical Research Network protocol to reduce cerebrospinal fluid shunt infection. J Neurosurg Pediatr 17:391-396, 2016

26. Kestle JR, Riva-Cambrin J, Wellons JC III, Kulkarni AV, Whitehead WE, Walker ML, et al: A standardized protocol to reduce cerebrospinal fluid shunt infection: the Hydrocephalus Clinical Research Network Quality Improvement Initiative. J Neurosurg Pediatr 8:22-29, 2011

27. Khan A, Nakamura MM, Zaslavsky AM, Jang J, Berry JG, Feng JY, et al: Same-hospital readmission rates as a measure of pediatric quality of care. JAMA Pediatr 169:905-912, 2015

28. Kocher RP, Adashi EY: Hospital readmissions and the Affordable Care Act: paying for coordinated quality care. JAMA 306:1794-1795, 2011

29. Lavernia CJ, Villa JM, Iacobelli DA: Readmission rates in the state of Florida: a reflection of quality? Clin Orthop Relat Res 471:3856-3862, 2013

30. Modhia U, Takemoto S, Braid-Forbes MJ, Weber M, Berven $\mathrm{SH}$ : Readmission rates after decompression surgery in patients with lumbar spinal stenosis among Medicare beneficiaries. Spine (Phila Pa 1976) 38:591-596, 2013

31. Mukerji N, Jenkins A, Nicholson C, Mitchell P: Unplanned reoperation rates in pediatric neurosurgery: a single center experience and proposed use as a quality indicator. J Neurosurg Pediatr 9:665-669, 2012

32. Neuman MI, Hall M, Gay JC, Blaschke AJ, Williams DJ, Parikh K, et al: Readmissions among children previously hospitalized with pneumonia. Pediatrics 134:100-109, 2014

33. Rangrass G, Ghaferi AA, Dimick JB: Explaining racial disparities in outcomes after cardiac surgery: the role of hospital quality. JAMA Surg 149:223-227, 2014

34. Rosenthal MB: Beyond pay for performance-emerging models of provider-payment reform. N Engl J Med 359:1197-1200, 2008

35. Sarda S, Bookland M, Chu J, Shoja MM, Miller MP, Reisner $\mathrm{SB}$, et al: Return to system within 30 days of discharge following pediatric non-shunt surgery. J Neurosurg Pediatr 14:654-661, 2014

36. Schairer WW, Carrer A, Deviren V, Hu SS, Takemoto S,
Mummaneni $\mathrm{P}$, et al: Hospital readmission after spine fusion for adult spinal deformity. Spine (Phila Pa 1976) 38:16811689,2013

37. Shah MN, Stoev IT, Sanford DE, Gao F, Santiago P, Jaques DP, et al: Are readmission rates on a neurosurgical service indicators of quality of care? J Neurosurg 119:1043-1049, 2013

38. Sherrod BA, Arynchyna AA, Johnston JM, Rozzelle CJ, Blount JP, Oakes WJ, et al: Risk factors for surgical site infection following nonshunt pediatric neurosurgery: a review of 9296 procedures from a national database and comparison with a single-center experience. J Neurosurg Pediatr 19:407-420, 2017

39. Shih T, Chen LM, Nallamothu BK: Will bundled payments change health care? Examining the evidence thus far in cardiovascular care. Circulation 131:2151-2158, 2015

40. Springel T, Laskin B, Furth S: Readmission within 30 days of hospital discharge among children receiving chronic dialysis. Clin J Am Soc Nephrol 9:536-542, 2014

41. Srivastava R, Keren R: Pediatric readmissions as a hospital quality measure. JAMA 309:396-398, 2013

42. Tejedor-Sojo J, Singleton LM, McCormick K, Wrubel D, Chern JJ: Preventability of pediatric 30-day readmissions following ventricular shunt surgery. J Pediatr 167:1327-1333, 1333.e1, 2015

43. Underwood MA, Danielsen B, Gilbert WM: Cost, causes and rates of rehospitalization of preterm infants. J Perinatol 27:614-619, 2007

44. Vaziri S, Cox JB, Friedman WA: Readmissions in neurosurgery: a qualitative inquiry. World Neurosurg 82:376-379, 2014

45. Wang MC, Shivakoti M, Sparapani RA, Guo C, Laud PW, Nattinger AB: Thirty-day readmissions after elective spine surgery for degenerative conditions among US Medicare beneficiaries. Spine J 12:902-911, 2012

46. Wrubel DM, Riemenschneider KJ, Braender C, Miller BA, Hirsh DA, Reisner A, et al: Return to system within 30 days of pediatric neurosurgery. J Neurosurg Pediatr 13:216-221, 2014

47. Young PC, Korgenski K, Buchi KF: Early readmission of newborns in a large health care system. Pediatrics 131:e1538-e1544, 2013

\section{Disclosures}

The authors report no conflict of interest concerning the materials or methods used in this study or the findings specified in this paper.

\section{Author Contributions}

Conception and design: Chotai, Shannon, Wellons, Naftel. Acquisition of data: Chotai, Guidry, Chan, Sborov, Gannon, Shannon. Analysis and interpretation of data: Chotai. Drafting the article: Chotai, Guidry. Critically revising the article: Chotai, Guidry, Gannon, Shannon, Bonfield, Wellons, Naftel. Reviewed submitted version of manuscript: Chotai, Guidry, Chan, Sborov, Gannon, Bonfield, Wellons, Naftel. Approved the final version of the manuscript on behalf of all authors: Chotai. Statistical analysis: Chotai. Administrative/technical/material support: Guidry, Sborov, Gannon, Shannon, Naftel. Study supervision: Shannon, Bonfield, Wellons, Naftel.

\section{Correspondence}

Silky Chotai, Surgical Outcomes Center for Kids, Department of Neurological Surgery, Division of Pediatric Neurosurgery, Vanderbilt University Medical Center, 2220 Children's Way, 9226 Doctors' Office Tower, Nashville, TN 37232-9557. email: silky. chotai@vanderbilt.edu. 